\title{
Maximum and Minimum Void Ratios for Sand-Silt Mixtures
}

\author{
C. S. Chang ${ }^{1}$, J.Y. Wang ${ }^{2}$ and L. Ge ${ }^{2}$
}
${ }^{1}$ Department of Civil and Environmental Engineering, University of Massachusetts, Amherst, MA 01002;
${ }^{2}$ Department of Civil Engineering, National Taiwan University, Taipei, 10617, Taiwan.

\section{ABSTRACT}

Minimum and maximum void ratios provide a general basis for comparative evaluation of material properties for soils with various densities. Either the minimum or the maximum void ratio is dependent considerably upon the fines content of soil. There are a few mathematical models in the literature for predicting the variation of minimum void ratio with respect to fines content. However, mathematical models for predicting maximum void ratio with respect to fines content are very limited in the field of geotechnical engineering. This study shows that the variation of maximum void ratio with respect to fines content of a sand-silt mixture is caused by the same mechanisms that influence the variation of minimum void ratio. Consequently, the mathematical model previously proposed by the authors for predicting minimum void ratios of sand-silt mixtures is extended to be capable of predicting the maximum void ratios of sand-silt mixtures due to the influence of fines content. The applicability of this extended mathematical model is verified by data from 24 sand-silt mixtures with various fines contents. Furthermore, based on the extended mathematical model, the relationship between the maximum and the minimum void ratios of a sand-silt mixture can be derived. The derived relationship is found to be linear and is a function of fines content. The validity of the derived linear relationship between the maximum and the minimum void ratios of a sand-silt mixture is also verified by the measured results from experiments.

Key words: sand-silt mixture, fines content, maximum void ratio, minimum void ratio, grain size.

\section{INTRODUCTION}

The values of maximum and minimum void ratios represent the loosest and densest conditions for soil, which can be used to assess the relative density of soil in situ. It has been clearly demonstrated that the relative density and the range of $e_{\max }-e_{\min }$ are key parameters for estimating the behavior of soil (Selig and Ladd 1973; Cubrinovski and Ishihara 2002). Experimentally, the values of maximum and minimum void ratios can be determined according to the procedures specified in ASTM (D4253 and D4254), Japanese Soil Testing Standard (2000), and several other methods in the literature (Kolbuszewski, 1948;Mulilis et al., 
1977; Vaid and Negussey, 1988). These methods may provide somewhat different values for the two extreme void ratios (Tavena et al., 1973).

The values of maximum or minimum void ratios for sand are related to several factors: the particle shape, the mean particle size, the uniformity coefficient $\mathrm{C}_{\mathrm{u}}$, and the mechanical procedures from which the extreme void ratios are determined. There are a few experimental studies that provide empirical relations for maximum or minimum void ratio as a function of particle shape, uniformity and mean particle size for clean sand (Selig and Ladd, 1973; Youd, 1973; Santamarina and Cho, 2004; Cho et al., 2006).

For sand-silt mixtures, the main factor influencing maximum and minimum void ratios is fines content, which represents the particle size distribution of a mixture. Since the packing structure is greatly influenced by the particle size distribution, it is not surprising that the amount of fines in a sand-silt mixture has significant effects on its mechanical properties (Selig and Ladd, 1973; Aberg, 1992; Miurai et al., 1998; Cubrinovski and Ishihara, 2002; Bobei et al., 2009; Peters and Berney, 2010; Fuggle et al., 2014). Experimental results have shown that the amount of fines content can influence many aspects of soil behavior such as compressional behavior, strength, steady state line, static liquefaction, undrained fragility, and instability behavior (Salgado et al., 2000; A.B. and G.Papageorigou, 2001; Fourie et al., 2001; Chu and Leong, 2002; Thevanayagam et al., 2002; Monkul and Ozden, 2007; Cabalar et al., 2013; Cabalar and Mustafa, 2015).

The importance of fines content has also been observed in many branches in the industry, such as ceramics processing (Reed, 1995), powder metallurgy (Smith, 2003), and concrete mixes (Powers, 1968). Early studies of packing density as a function of fines content can be found by Westman and Hugill (1930) and McGeary (1961). In the 1980s, analytical methods have been refined to account for the effect of particle size ratio by Stovall et al. (1986), Yu and Standish (1987) in the field of powder mixture, and by De Larrard (1999) in the field of concrete mixture. These methods have been used for concrete mixture design to optimize the packing densities of cement, mortar and concrete (e.g., Kwan and Fung, 2009; Fennis et al., 2013).

For soils, a graphical method of estimating maximum packing density of soil with different sizes of particles was proposed by Humphres (1957) using an empirical approach. Around 1986, AASHTO T224-86 specifications postulate an empirical rule for estimating the maximum packing density of gravel-soil mixtures. Kezdi (1979) outlined an analytical method to estimate the minimum porosity of a binary mixture of granular soils. This method is only applicable to packings of very small fine particles and often overestimates the maximum packing density (Vallejo, 2001). For improving compaction control of granular fill, Fragaszy and Sneider (1991) carried out an extensive set of experiments on soils with a wide range of particle sizes, and compared the measured maximum dry densities with that predicted from the two empirically based methods: "Humphres method (Humphres, 1957)" and "AASHTO correction factor" method (AASHTO T224-86). In association with the liquefaction potential of silty-sand, Lade et al. (1998) 
had carried out minimum void ratio tests for different types of sand-silt mixtures. They also proposed an analytical method for predicting the minimum void ratio for spheres with different sizes. This method, similar to that of Kezdi (1979), also suffers the limitation of overestimating the packing density. Cubrinovski and Ishihara (2002) examined a large number of test data on silty-sand and presented a set of empirical equations to show the influence of fines content on the magnitude of minimum void ratio. Another line of study related to sand-silt mixtures is the concept of skeleton void ratio (Mitchell, 1993; Vaid, 1994) or termed as inter-granular void ratio (Thevanayagam 1998), which is not the real void ratio of the sand-silt mixture, but a combined function of the real void ratio and the fines content. The inter-granular void ratio has been used to correlate the static and cyclic strength of sand-silt mixtures (Thevanayagam et al., 2002; Yang et al., 2005 ). Although the concept does not directly deal with the minimum or the maximum void ratio, it does provide insights on the connection between the void ratio and the packing structure of a sandsilt mixture. Apart from these studies, computer simulation analyses using the discrete element method (DEM) have also been implemented to study the characteristics of the void ratio for a mixture made of spherical particles of two different sizes (An, 2013; Fuggle et al., 2014). The trend of computer simulation results resembles that obtained from experimental tests. However, for mixtures of natural soil (such as sandsilt mixtures) with large ratio of particle sizes and complex particle shapes, it is necessary to use significantly large number of particles for the simulation. Thus, it makes the numerical simulation to be practically unfeasible.

Chang et al. (2015) proposed an analytical method that can predict the minimum void ratios for sand-silt mixtures with various particle size ratios and various fines contents. The developed model was evaluated by experimental results on 33 types of sand-silt mixtures. The evaluation has shown good agreement between the predicted and the measured values.

Compared to the number of studies on minimum void ratio (or densest packing), the number of studies on mathematical models for maximum void ratio (loosest packing) is rather limited. In the present paper, we aim to extend the previously proposed minimum void ratio model to have the capability of predicting both minimum and maximum void ratios for sand-silt mixtures. We also aim to derive mathematical relationships between the maximum and the minimum void ratios for sand-silt mixtures. 


\section{EFFECT OF FINES CONTENT ON THE MINIMUM VOID RATIO OF A BINARY MIXTURE}

The minimum void ratio is 0.35 for a hexagonal packing of monosize spheres. The minimum void ratio for a packing of randomly arranged monosize spheres is about 0.56-0.66 (Dullien, 1992). The particle shape has noteworthy influence on the minimum void ratio of a packing. The minimum void ratio for a packing of angular particles is generally higher than that for a packing of spherical particles. For binary mixtures of particles, the influence of fines content on packing density can be highlighted by the experimental results (McGeary, 1961) on steel shots mixtures. Fig. 1 shows the variation of void ratio with respect to fines content for six binary mixtures. The six mixtures are comprised of large particles of $3.14 \mathrm{~mm}$ and six other smaller sizes (i.e, 0.91, 0.66, 0.48, 0.28, 0.19, $0.16 \mathrm{~mm}$ ).

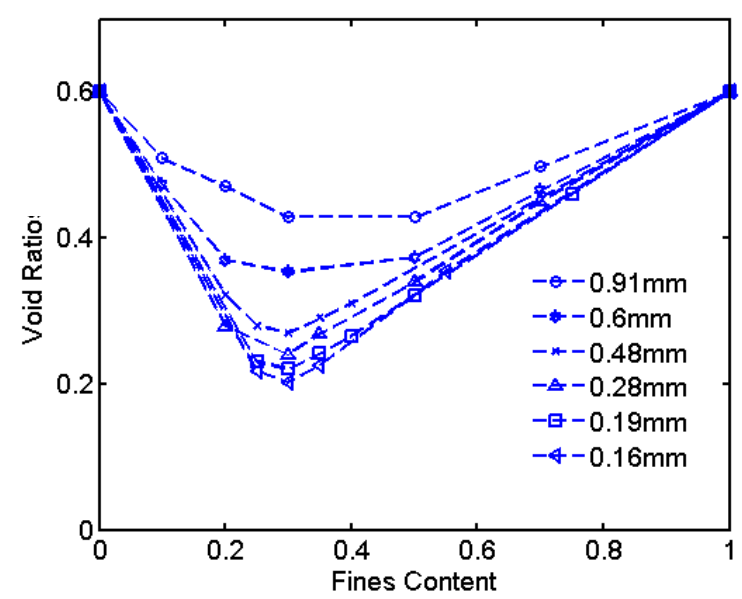

Fig. 1. Binary packing of steel shots (Data obtained from McGeary, 1961).

Two characteristics of the variation of void ratio can be observed in this figure: (1) the curves showing the variation of void ratio with respect to fines content are V-shaped, and (2) the shape of these curves is significantly dependent on the size ratio of coarse particles to fine particles. Although the experiment's results were obtained from spherical shaped steel shots, it is interesting to note that these two characteristics are also displayed by the experimental result of sand-silt mixtures, even though the shape characteristics of soil particles are very different from that of steel shots.

It was recognized by McGeary (1961) that there are two distinct types of packing structures of the steel shots mixtures. The two packing structures are schematically presented in Fig. 2. For lower fines content, the packing structure is coarse-grain dominant with fine particles filled into the void space among the coarse grains. For the high fines content, the packing structure is fine-grain dominant with coarse particles inclusions embedded in the fines. McGeary considered that the change of packing structure is the main factor that influences the variation of void ratio with respect to fines content. 


\section{MODEL FOR MINIMUM VOID RATIO OF SAND-SILT MIXTURES}

A sand-silt mixture is considered to be a two-phase material. The phase diagrams corresponding to the two packing structures shown in Fig.2 are constructed here in Fig. 3 and Fig. 4. For the coarse-grain dominant packing structure, the phase diagram can be plotted in Fig. 3.

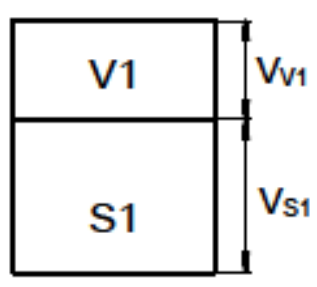

(a)

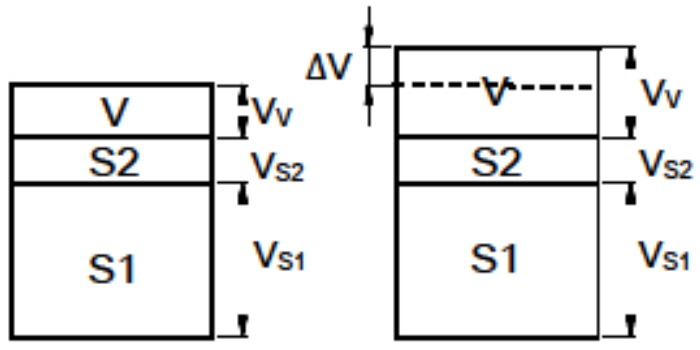

(b)

(c)

Fig. 3. Phase diagrams: (a) Clean sand (before silt is added); (b) Mixture (limiting case); (c) Mixture (general case).

Fig. 3(a) shows the phase diagram of clean sand (S1 is the solid phase, and V1 is the void phase). Its void ratio is defined as the volumetric ratio of void to solid $e_{1}=V_{v 1} / V_{s 1}$. Fig. 3(b) shows the limiting case of a sand-silt mixture where the silt particles (S2) are filled into to the void space among sand grains (V1) 
without a change in the total volume (i.e. $V_{v}+V_{s 2}=V_{v 1}$ ). Fig. 3(c) shows a general case where the packing structure is disturbed with a change in total volume denoted as $\Delta V$. The void volume of the sand-silt mixture is $V_{v}$. The change in void volume is defined as $\Delta V_{v}=V_{v}-V_{v 1}$. Since $V_{v}=V_{v 1}+\Delta V-V_{s 2}$ (Fig. 3(c)). Thus the change in void volume can be expressed as $\Delta V_{v}=\Delta V-V_{s 2}$. For the limiting case, $\Delta V=0$ and the change in void volume $\Delta V_{v}=-V_{s 2}$, i.e., the void volume is decreased by the amount of solid volume of silt filled into the void space.

For the fine-grain dominant packing structure, the phase diagram can be plotted in Fig. 4. In this case, Fig. 4(a) shows the phase diagram of clean silt ( $\mathrm{S} 2$ is the solid phase and V2 is the void phase). The void ratio for the packing of clean silt $e_{2}=V_{v 2} / V_{s 2}$. Fig. 4(b) shows the limiting case where the sand particles are embedded into to the silt particles as isolated inclusions without a change in void volume. Thus, the solid volume of sand $\mathrm{S} 1$ is plotted below the solid volume of silt $\mathrm{S} 2$, while the void volume $V_{v}=V_{v 2}$. Fig. 4(c) shows a general case where the packing structure is disturbed with a change in void volume denoted as $\Delta V_{v}$. Note that $\Delta V_{v}=0$ is the limiting case.

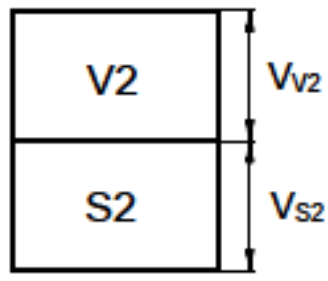

(a)

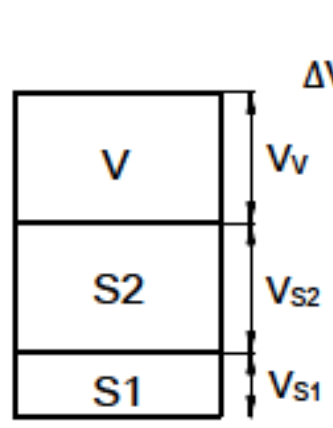

(b)

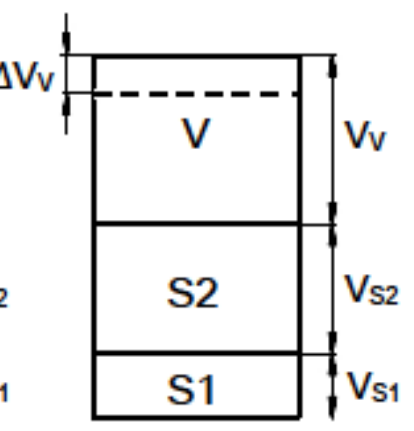

(c)

Fig. 4. Phase diagrams: (a) Clean silt (before sand is added); (b) Mixture (limiting case); (c) Mixture (general case).

Void ratio can be straightforwardly derived from the phase diagram. Thus, referring to the two different phase diagrams shown in Figs. 3 and 4, the void ratios of sand-silt mixtures corresponding to the two different packing structures can be derived from:

$$
\begin{array}{ll}
e_{M 1}=\frac{V_{v 1}+\Delta V_{v}}{V_{s 1}+V_{s 2}} & \text { for coarse-grain dominant packing structures, and } \\
e_{M 2}=\frac{V_{v 2}+\Delta V_{v}}{V_{s 1}+V_{s 2}} & \text { for fine-grain dominant packing structures. }
\end{array}
$$

It was shown by Chang et al (2015) that the change of void volume $\Delta V_{v}$ in Eqs. (1) and (2) can be expressed by the following form: 


$$
\Delta V_{v}=\left((1-a)\left(1+e_{2}\right)-1\right) V_{s 2} \text { for coarse-grain dominant packing structures, and }
$$$$
\Delta V_{v}=(1-b) e_{1} V_{s 1} \quad \text { for fine-grain dominant packing structures. }
$$

where $V_{s 1}, V_{s 2}$ are the solid volume for sand and silt in the mixture, and $e_{1}, e_{2}$ are the minimum void ratios for clean sand and clean silt respectively. For both parameters $a$ and $b$, the value range is between 1 and 0 . The parameter $a$ is termed as filling coefficient. The condition of $a=1$ corresponds to the change in void volume $\Delta V_{v}=-V_{s 2}$, indicating that silt particles are perfectly filled into the voids among sand without a change of total volume. The parameter of $b$ is termed as embedment coefficient. The condition of $b=1$ corresponds to the change in void volume $\Delta V_{v}=0$, indicating a perfect condition of sand particles embedded in the silt matrix. On the other hand, the conditions of $a=0$ and $b=0$ corresponds to the maximum change in void volume $\Delta V_{v}$ due to the disturbance of the mixture.

For a sand-silt mixture, let $y_{1}$ and $y_{2}$ be the solid volume fraction for sand and silt respectively (i.e., $\left.y_{1}=V_{s 1} /\left(V_{s 1}+V_{s 2}\right) ; y_{1}+y_{2}=1\right)$. The value of $y_{2}$ is also termed as the fines content of this sand-silt mixture. Equations (1)-(4) lead to the following expressions:

$$
\begin{aligned}
& e_{M 1}=e_{1} y_{1}+e_{2} y_{2}-a\left(1+e_{2}\right) y_{2} \quad \text { for coarse-grain dominant packing structures, and } \\
& e_{M 2}=e_{1} y_{1}+e_{2} y_{2}-b e_{1} y_{1} \quad \text { for fine-grain dominant packing structures. }
\end{aligned}
$$

For a sand-silt mixture with a given fines content, two values ( $e_{M 1}$ and $\left.e_{M 2}\right)$ can be computed using Eqs. (5) and (6). Based on the principle of least energy, the greater of the two is the predicted void ratio $e_{M}$ of the sand-silt mixture. (i.e., $e_{M}=\max \left(e_{M 1}, e_{M 2}\right)$ ). The Eqs. (5) and (6) provide a mathematical model that describe the variation of void ratios with fines content of a sand-silt mixture.

The variation of void ratio computed from Eqs.(5) and (6) has the following features:

(1) For fines content $y_{2}<y_{2 T}$, the computed values show that $e_{M}=e_{M 1}>e_{M 2}$, which corresponds to the coarse-grain dominant region.

(2) For a specific value of fines content $y_{2}=y_{2 T}$, the computed value shows that $e_{M}=e_{M 1}=e_{M 2}$.

(3) For fines content $y_{2}>y_{2 T}$, the computed values show that $e_{M}=e_{M 2}>e_{M 1}$, which corresponds to the fine-grain dominant region.

The predicted curves of minimum void ratio versus fines content are two lines in a V-shape. The two lines intersect at the bottom point of $\mathrm{V}$, which corresponds to the fines content equal to $y_{2 T}$. The specific fines content $y_{2 T}$ is the boundary point of the coarse-grain dominant region and fine-grain dominant region. This specific fines content corresponding to the boundary point is termed threshold fines content (TFC) by Thevanayagam et al. (2002), transitional fines content by Yang et al. (2005) or Limiting fines content by Polito and Martin (2001). 


\section{EXTENSION OF THE MODEL TO MAXIMUM VOID RATIO OF A SAND-SILT MIXTURE}

The opposite extreme of the minimum void ratio is the maximum void ratio corresponding to the loosest condition of a sand-silt mixture. The maximum void ratio is 0.91 for a simple cubic packing of monosize spheres. The maximum void ratio for a packing of randomly arranged monosize spheres is about 0.70-0.80 (Dullien, 1992). The particle shape has noteworthy influence on the maximum void ratio of a packing. The maximum void ratio for a packing of angular particles is generally higher than that for a packing of spherical particles. Here, we aim to extend the method, described above for predicting minimum void ratios, to have the capability for predicting maximum void ratios with the influence of fines content.

Characteristics of maximum void ratios for binary packings are very similar to that of minimum void ratios. The experimental results for Silica sand-silt mixtures (Yilmaz, 2009) are shown in Fig. 5. Silica sandsilt mixtures are made up of commercially available Pasabahce silica sand, which is artificially graded using a variety of sieves into 12 subgroups with mean particle sizes $(1.08 \mathrm{~mm}, 0.78 \mathrm{~mm}, 0.4 \mathrm{~mm}, 0.42 \mathrm{~mm}, 0.26$ $\mathrm{mm}, 0.17 \mathrm{~mm}, 0.14 \mathrm{~mm}, 0.13 \mathrm{~mm}, 0.10 \mathrm{~mm}, 0.09 \mathrm{~mm}, 0.05 \mathrm{~mm}$ ). The numbers shown in Fig. 5 are ASTM sieve numbers. The coarsest grains of $1.08 \mathrm{~mm}$ are mixed individually with the other 11 subgroups. Based on the experimental results by Yilmaz (2009), the curves show that, in the same manner as those of minimum void ratio, the maximum void ratio of a mixture is influenced by both the fines content and the particle size ratio.

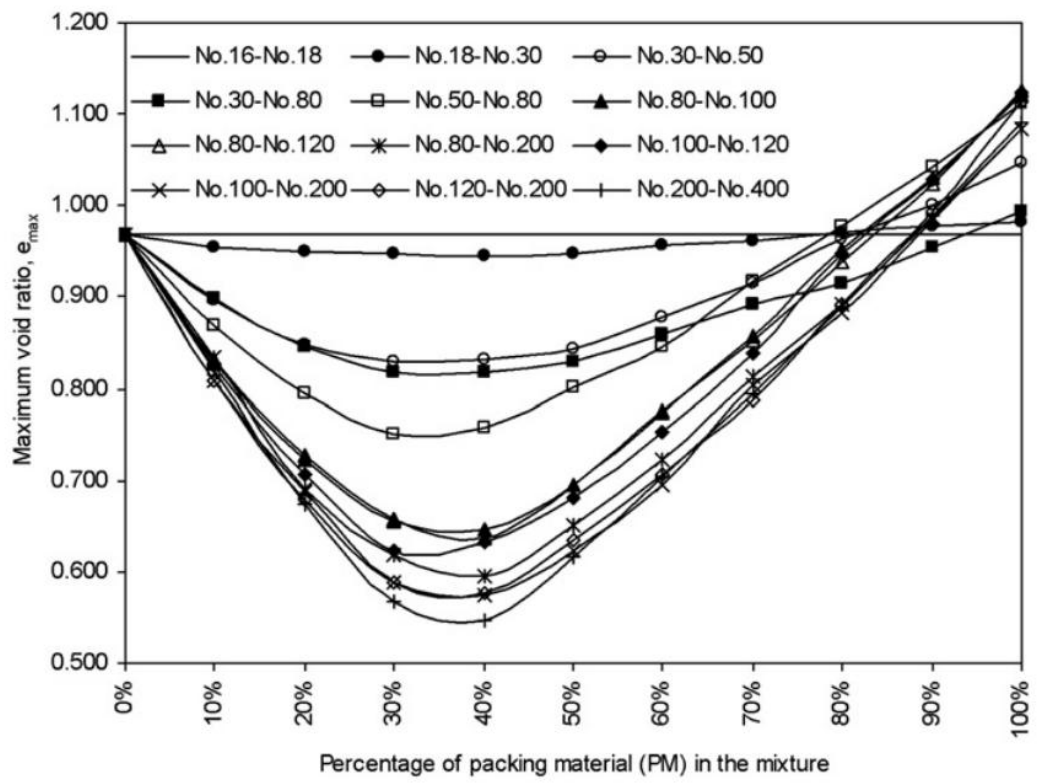

Fig. 5. Experimental results for maximum void ratios of Silica sand-silt mixtures (Yilmaz, 2009) 
Since the characteristics of maximum void ratios are very similar to that of the minimum void ratios due to the influence of fines content, it is logical to apply the same concept used in modelling minimum void ratio for the derivation of maximum void ratios as a function of fines content. Using the same process given in the previous section, we derive the equations for maximum void ratios in the following form

$$
\begin{aligned}
& e_{M 1}^{\max }=e_{1}^{\max } y_{1}+e_{2}^{\max } y_{2}-a^{\max }\left(1+e_{2}^{\max }\right) y_{2} \text { for coarse-grain dominant packing structures, and } \\
& e_{M 2}^{\max }=e_{1}^{\max } y_{1}+e_{2}^{\max } y_{2}-b^{\max } e_{1}^{\max } y_{1} \quad \text { for fine-grain dominant packing structure. }
\end{aligned}
$$

And the maximum void ratio of a sand-silt mixture is determined by $e_{M}^{\max }=\max \left(e_{M 1}^{\max }, e_{M 2}^{\max }\right)$. These two equations are compared with the derived equations for minimum void ratios, expressed by:

$$
\begin{aligned}
& e_{M}^{\min }=e_{1}^{\min } y_{1}+e_{2}^{\min } y_{2}-a^{\min }\left(1+e_{2}^{\min }\right) y_{2} \text { for coarse-grain dominant packing structures, and } \\
& e_{M}^{\min }=e_{1}^{\min } y_{1}+e_{2}^{\min } y_{2}-b^{\min } e_{1}^{\min } y_{1} \quad \text { for fine-grain dominant packing structures. }
\end{aligned}
$$

And the minimum void ratio of a sand-silt mixture is determined by $e_{M}^{\min }=\max \left(e_{M 1}^{\min }, e_{M 2}^{\min }\right)$.

Note that the two sets of equations have the same form. But, for the set of equations for maximum void ratios, the values of maximum void ratios for the clean sand and for the clean silt packing, $e_{1}^{\max }, e_{2}^{\max }$ and the values of parameters $a^{\max }, b^{\max }$ are designated to be different from the set of equations for minimum void ratios, as marked on the superscript.

The values of $a^{\min }, b^{\min }, a^{\max }, b^{\max }$ are tabulated for each sand-silt mixtures listed in Table 1 . These values are determined from experimental results using Eqs. (7-10). The values are also plotted in Fig. 6 to observe their correlation as a linear relationship of $a^{\max }=a^{\min }$ and $b^{\max }=b^{\min }$. The coefficient of determination $\mathrm{R}^{2}$ is 0.8509 .

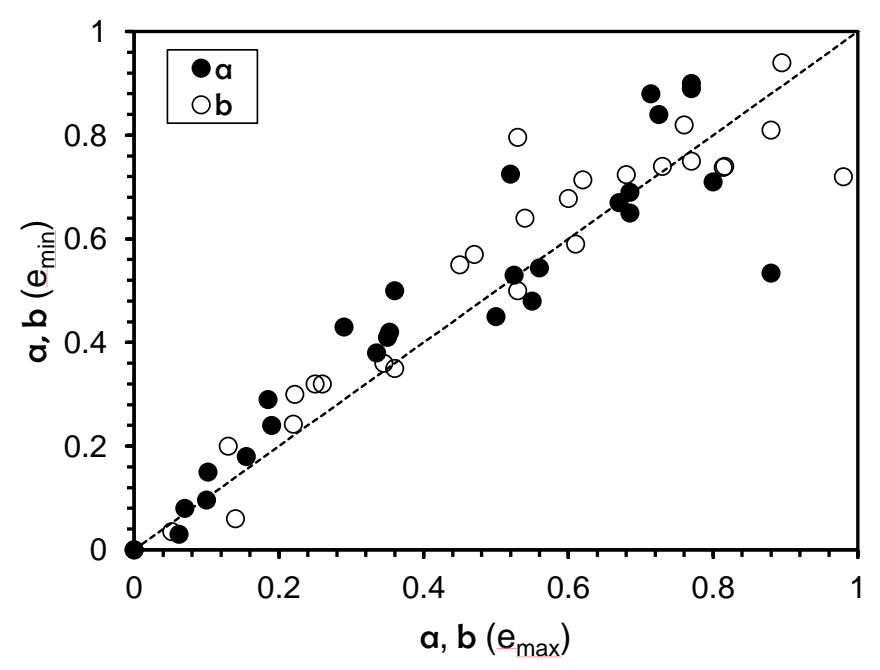

Fig. 6. Comparison of the values $a$ and $b$ obtained from minimum and maximum ratios tests. 
According to the theory proposed by Chang et al. (2015), the values of $a$ and $b$ are material parameters that governs the volume change due to the mix of two constituents of a binary packing. The two parameters are functions of the geometric characteristics of the two constituents, e.g. the particle size ratio and the particle shape characteristics of the two constituents of the sand-silt mixture. Therefore, for a binary mixture with the same two constituents, we expect that the values of $a$ and $b$, whether for the case of maximum or minimum void ratios, should have the same values. Thus, we expect that the correlation should be better than that shown in Fig. 6. However, it is noted that for natural soils, some degree of variation on particle shapes is unavoidable. The scattering can be attributed to the specimens of sand-silt mixtures that have variations in their shape characteristics.

To further investigate the applicability of the assumption (i.e., $a^{\max }=a^{\min }$, and $b^{\max }=b^{\min }$ ), we compare the predicted and the measured values of maximum void ratios. In Figs. 7(a) and 7(b), the predicted minimum void ratios using Eqs. (9) and (10) are plotted with dotted lines for 24 sand-silt mixtures (listed in Table 1). The predictions were calculated using the values of $a^{\text {min }}$ and $b^{\text {min }}$ determined directly from measured data. Whereas the maximum void ratios were predicted from two different ways: (1) using the $a^{\max }$ and $b^{\max }$ determined directly from the data of maximum void ratios; the predicted results are shown with solid lines. (2) using the assumption that $a^{\max }=a^{\min }$, and $b^{\max }=b^{\min }$; the predicted results are shown with dotted lines.

It is noted that both model predictions have some discrepancies with the measured data. The measured data of maximum void ratios and the predicted values from case 1 have an averaged coefficient of determination $\mathrm{R}^{2}=0.94$ for the 24 mixtures, whereas the measured data of maximum void ratios and the predicted values from case 2 have an averaged coefficient of determination $R^{2}=0.92$ for the 24 mixtures. The difference between the two predictions with respect to the measured data is not significant; the prediction of case 1 is only slightly better. It is noted that the goodness-of-fit of the predicted and measured void ratios shown in Figs. 7(a) and 7(b) $\left(\mathrm{R}^{2}=0.92-0.94\right)$ is better than the goodness-of-fit of the assumed and measured parameters shown in Fig. 6 (i.e., $\mathrm{R}^{2}=0.85$ for $a^{\max }=a^{\min }$, and $b^{\max }=b^{\text {min }}$ ). Since the goal of this model is to predict the values of maximum void ratios, applicability of the model is primarily evaluated by the level of agreement between the predicted and measured values. Therefore, the goodness-of-fit of Figs. 7(a) and 7(b) has more important inference than that of Fig. 6.

The comparisons in Figs. 7(a) and 7(b) demonstrate a fairly consistent agreement between the two predicted methods and measured results in the following aspects:

(1) The curves of measured data in Figs. 7(a) and 7(b) show that the slopes for maximum void ratios are very different from that for minimum void ratios. The predicted results can predominantly capture the inclinations of these slopes. 
(2) The measured points of transitional fines contents (i.e. the boundary points for the coarse-grain dominant region and the fine-grain dominant region) have different locations for maximum void ratios and minimum void ratios. The predicted results capture largely these locations.

Considering the goodness-of-fit in Fig. 6 and Fig. 7 and considering the variation of particle shapes of natural soil, it seems reasonable to adopt the hypothesis that the values of $a$ and $b$ are same for maximum and minimum void ratios. 

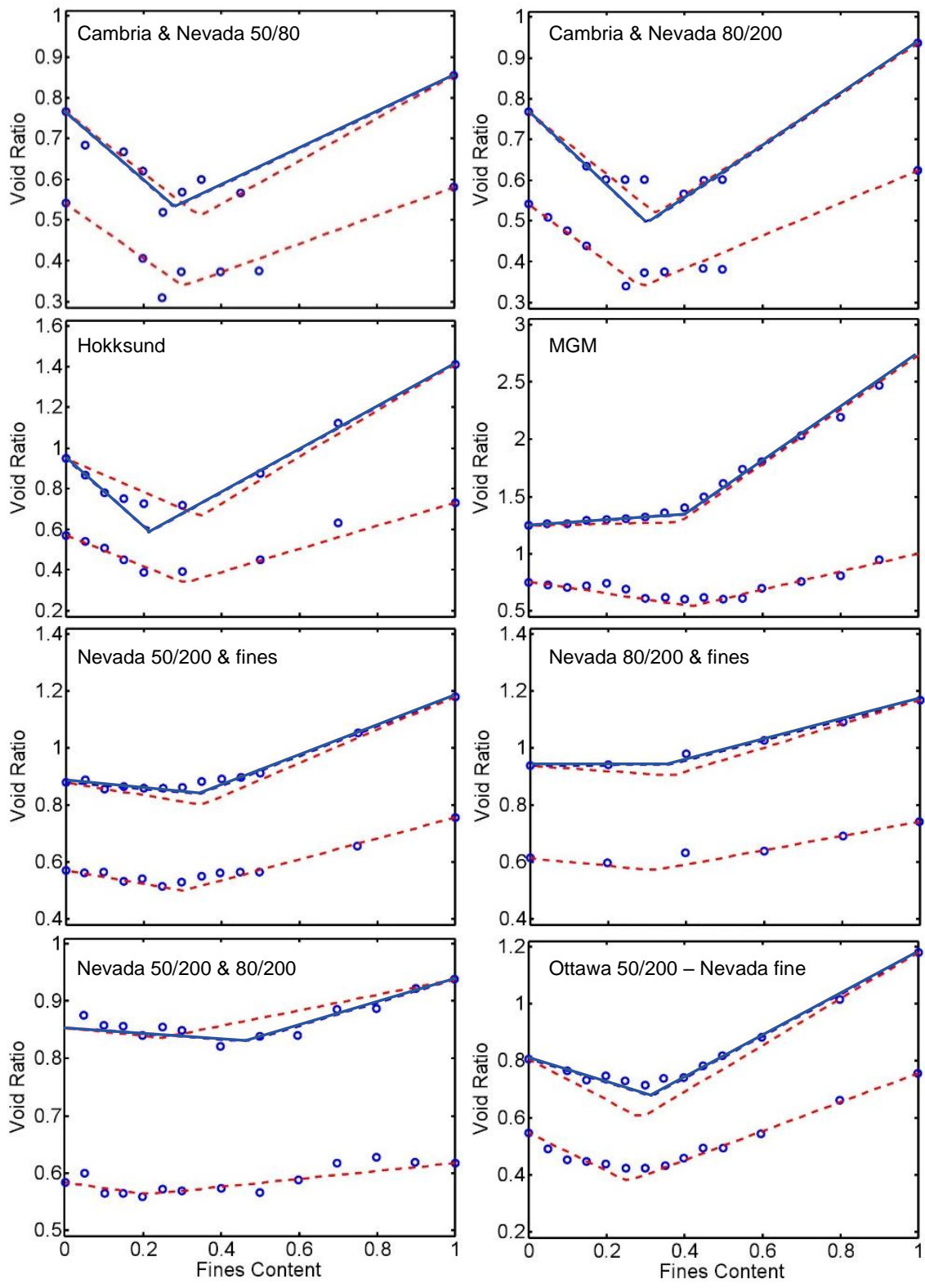
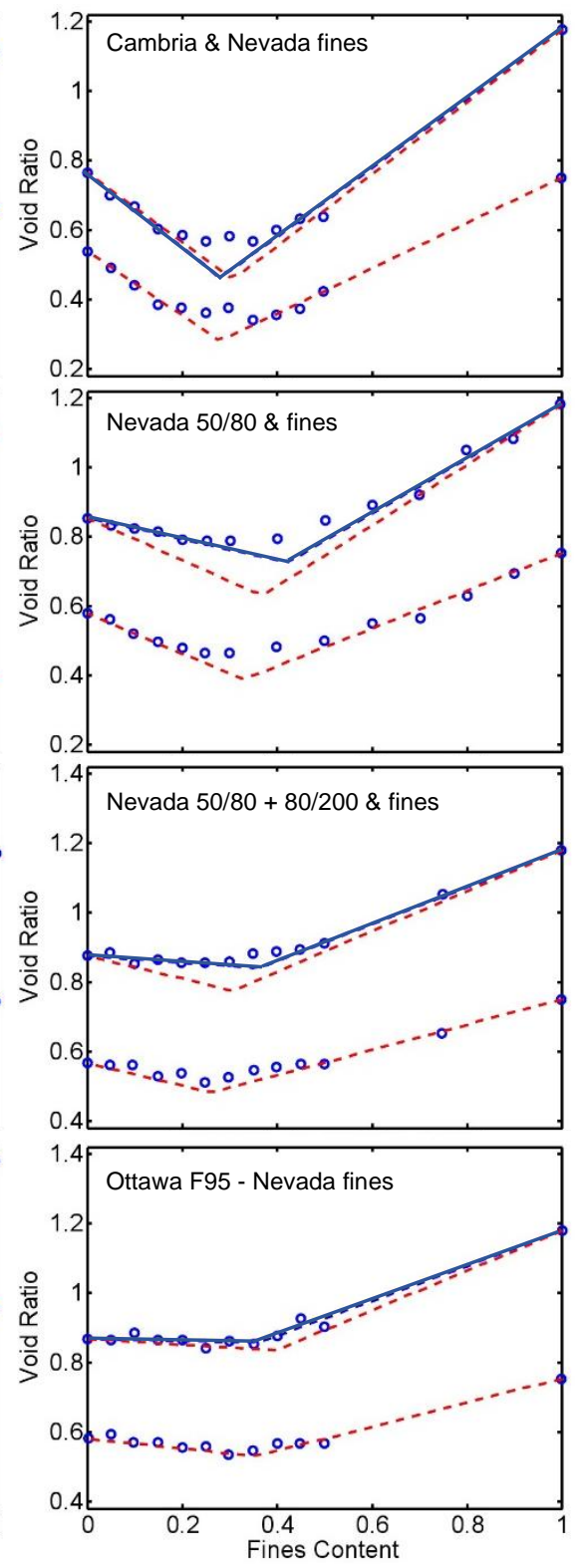

Fig. 7(a). Comparison of the measured and predicted maximum void ratios using the values $a$ and $b$ obtained from minimum void ratio tests listed in Table 1. 

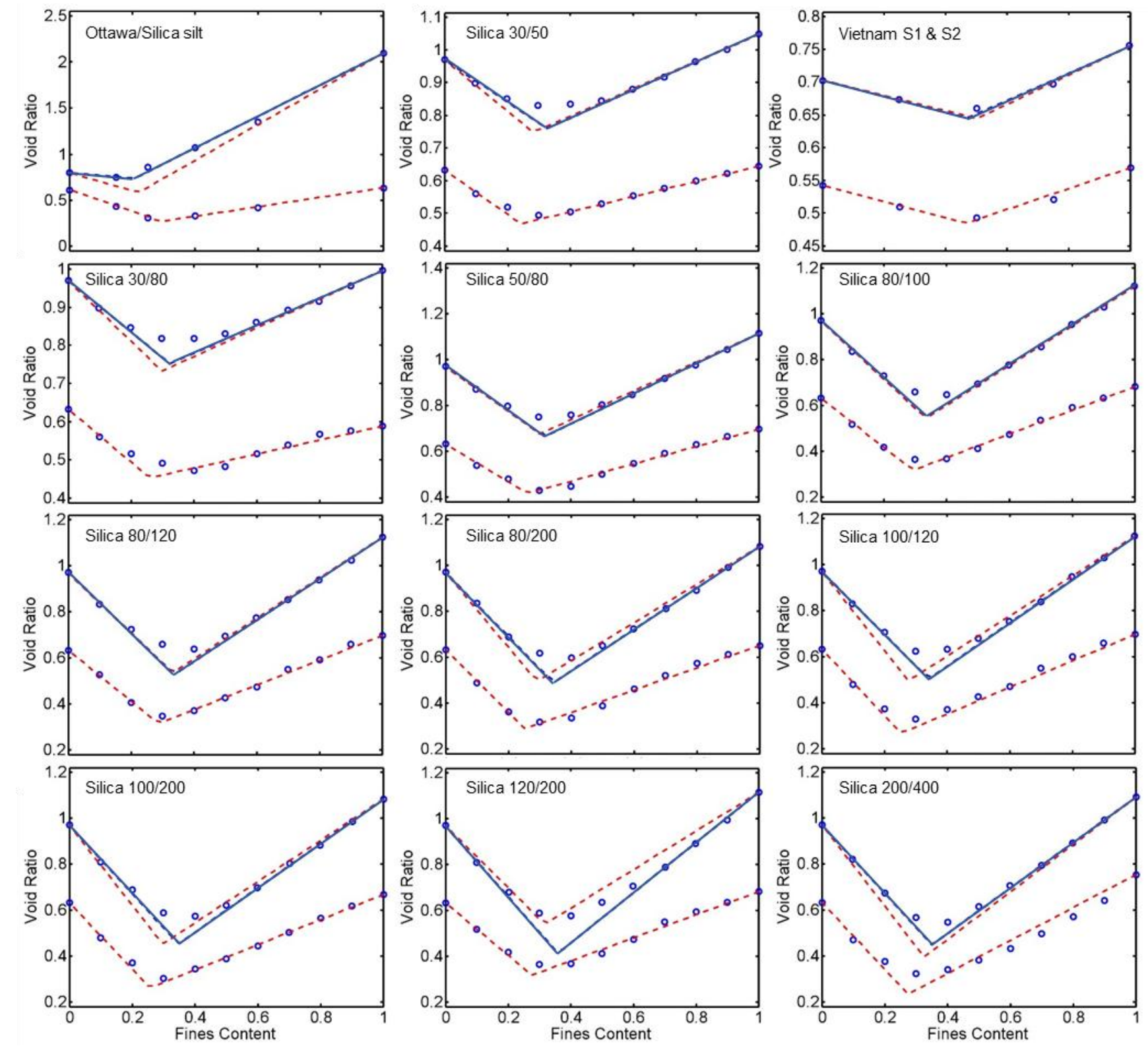

Fig. 7(b). Comparison of the measured and predicted maximum void ratios using the values $a$ and $b$ obtained from minimum void ratio tests listed in Table 1. 


\section{CORRELATION BETWEEN $e_{\max }$ AND $e_{\min }$ FOR SAND-SILT MIXTURE}

Geotechnical engineers have been interested in using minimum and maximum void ratios to provide a comparative evaluation of the field density. Empirical correlations have been studied from experimentally measured data on sand-silt mixtures (Cubrinovski \& Ishihara (2002). However, the empirical correlations are highly dependent on the fines content and the constituents of the sand-silt mixture. Thus, these empirical correlations can be used only for a specific type of sand-silt mixture, but they are difficult to be used in a general condition. Using the mathematical expressions developed in the previous section for minimum and maximum void ratios of a sand-silt mixture, we aim to derive a general mathematical expressions for the relationship between the maximum and the minimum void ratios.

By adopting the hypothesis that the parameters $a$ and $b$ are identical for maximum and minimum void ratios, the equations (7-10) for minimum and maximum void ratios for sand-silt mixtures can be listed below in two regions:

1) The coarse-grain dominant region $\left(e_{M}^{\max }=e_{M 1}^{\max }\right)$

$$
\begin{aligned}
& e_{M}^{\max }=e_{1}^{\max } y_{1}+e_{2}^{\max } y_{2}-a\left(1+e_{2}^{\max }\right) y_{2} \\
& e_{M}^{\min }=e_{1}^{\min } y_{1}+e_{2}^{\min } y_{2}-a\left(1+e_{2}^{\min }\right) y_{2}
\end{aligned}
$$

2) The fine-grain dominant region $\left(e_{M}^{\max }=e_{M 2}^{\max }\right)$

$$
\begin{aligned}
& e_{M}^{\max }=e_{1}^{\max } y_{1}+e_{2}^{\max } y_{2}-b e_{1}^{\max } y_{1} \\
& e_{M}^{\min }=e_{1}^{\min } y_{1}+e_{2}^{\min } y_{2}-b e_{1}^{\min } y_{1}
\end{aligned}
$$

Where $e_{1}^{\max }, e_{1}^{\min }, e_{2}^{\max }, e_{2}^{\min }$ are the maximum and minimum void ratios of sand and silt respectively. The values of $y_{1}$ and $y_{2}$ are the solid volume fractions of sand and silt respectively (i.e. $y_{1}+y_{2}=1$ ). The magnitude of $y_{2}$ is termed fines content.

Now we assume that the correlation between $e_{M}^{\max }$ and $e_{M}^{\min }$ has a linear relationship with constants $\alpha$ and $\beta$, given by

$$
e_{M}^{\max }=\alpha e_{M}^{\min }+\beta
$$

In the following, we can prove that this linear relationship is valid based on the proposed model. Furthermore, we derive the explicit expressions for the constants $\alpha$ and $\beta$. The derived expressions are different for the coarse-grain dominant region and for the fine-grain dominant region.

(1) coarse-grain dominant region 
Substituting Eqs. (11) and (12) into Eq. (15), the linear relationship of Eq. (15) becomes

$$
e_{1}^{\max } y_{1}+e_{2}^{\max } y_{2}-a_{12}\left(1+e_{2}^{\max }\right) y_{2}=\alpha\left(e_{1}^{\min } y_{1}+e_{2}^{\min } y_{2}-a_{12}\left(1+e_{2}^{\min }\right) y_{2}\right)+\beta
$$

In this equation, $y_{1}$ and $y_{2}$ represent one variable $\left(y_{2}=1-y_{1}\right)$. For any value of $y_{1}$, Eq. (16) must be satisfied. Thus, two equations can be established by specifying two given conditions of $y_{1}$, and the two unknown constants $\alpha$ and $\beta$ can be solved by these two equations.

(a) For the condition of clean sand, i.e., $y_{1}=1$ and $y_{2}=0$, Eq. (16) becomes

$$
e_{1}^{\max }=\alpha e_{1}^{\min }+\beta
$$

It is noted that $e_{1}^{\max }$ and $e_{1}^{\min }$ are two known constants; they are the maximum and minimum void ratios of clean sand.

(b) For the condition of a given fines content $f$, i.e., $y_{1}=1-f$ and $y_{2}=f$, Eq. (16) becomes

$$
(1-f) e_{1}^{\max }+f e_{2}^{\max }-f a\left(1+e_{2}^{\max }\right)=\alpha\left((1-f) e_{1}^{\min }+f e_{2}^{\min }-f a\left(1+e_{2}^{\min }\right)\right)+\beta
$$

With the two conditions, the two unknown constants $\alpha$ and $\beta$ can then be solved by the two simultaneous equations (17) and (18). Subtracting Eq. (17) from Eq. (18), $f$ can be factored out and $\alpha$ can be solved. Then $\beta$ can be obtained from Eq. (17). The solutions are given by:

$$
\alpha=\frac{e_{1}^{\max }-e_{2}^{\max }+a\left(1+e_{2}^{\max }\right)}{e_{1}^{\min }-e_{2}^{\min }+a\left(1+e_{2}^{\min }\right)} ; \quad \beta=e_{1}^{\max }-\alpha e_{1}^{\min }
$$

Thus the linear relationship between minimum and maximum void ratios is derived. The slope $\alpha$ and the intercept $\beta$ are functions of $e_{1}^{\max }, e_{1}^{\min }, e_{2}^{\max }, e_{2}^{\min }$, and $a$.

For the ideal condition $(a=b=1), \mathrm{Eq}(19)$ is reduced to

$$
\alpha=\frac{1+e_{1}^{\max }}{1+e_{1}^{\min }} \quad ; \quad \beta=\frac{e_{1}^{\max }-e_{1}^{\min }}{1+e_{1}^{\min }}
$$

For the limiting condition ( $a=b=0)$, Eq. (19) is reduced to

$$
\alpha=\frac{e_{1}^{\max }-e_{2}^{\max }}{e_{1}^{\min }-e_{2}^{\min }} ; \quad \beta=\frac{e_{2}^{\max } e_{1}^{\min }-e_{1}^{\max } e_{2}^{\min }}{e_{1}^{\min }-e_{2}^{\min }}
$$

(2) fine-grain dominant region 
Substituting Eqs. (13) and (14) into Eq. (15), the linear relationship of Eq. (15) becomes

$$
e_{1}^{\max } y_{1}+e_{2}^{\max } y_{2}-b e_{1}^{\max } y_{1}=\alpha\left(e_{1}^{\min } y_{1}+e_{2}^{\min } y_{2}-b e_{1}^{\min } y_{1}\right)+\beta
$$

Similar to the solution process above, two equations can be established from Eq. (23) by specifying two given conditions of $y_{1}$, and the two unknown constants $\alpha$ and $\beta$ can be solved by these two equations. The two conditions are as follows:

(a) For the condition of clean silt, i.e., $y_{1}=0$ and $y_{2}=1$, Eq. (22) becomes

$$
e_{2}^{\max }=\alpha e_{2}^{\min }+\beta
$$

(b) For the condition of a given fines content $f$, i.e., $y_{1}=1-f$ and $y_{2}=f$, Eq. (22) becomes

$$
(1-f) e_{1}^{\max }+f e_{2}^{\max }-(1-f) b e_{1}^{\max }=\alpha\left((1-f) e_{1}^{\min }+f e_{2}^{\min }-(1-f) b e_{1}^{\min }\right)+\beta
$$

The two constants $\alpha$ and $\beta$ can be solved by the two simultaneous equations (23) and (24). Subtracting Eq. (23) from Eq. (24), $f$ can be factored out and $\alpha$ can be solved. Then $\beta$ can be obtained from Eq. (17). The solutions are given by:

$$
\alpha=\frac{-e_{1}^{\max }+e_{2}^{\max }+b e_{1}^{\max }}{-e_{1}^{\min }+e_{2}^{\min }+b e_{1}^{\min }} \quad ; \quad \beta=e_{2}^{\max }-\alpha e_{2}^{\min }
$$

Thus the linear relationship of Eq. (23) is derived. The slope $\alpha$ and the intercept $\beta$ are functions of $e_{1}^{\max }, e_{1}^{\min }$ $, e_{2}^{\max }, e_{2}^{\min }$, and $b$

For the ideal condition ( $a=b=1), \mathrm{Eq}(25)$ is reduced to

$$
\alpha=\frac{e_{2}^{\max }}{e_{2}^{\min }} ; \beta=0
$$

For the limiting condition $(a=b=0), \mathrm{Eq}(25)$ is reduced to

$$
\alpha=\frac{e_{2}^{\max }-e_{1}^{\max }}{e_{2}^{\min }-e_{1}^{\min }} ; \beta=\frac{e_{2}^{\max } e_{1}^{\min }-e_{1}^{\max } e_{2}^{\min }}{e_{1}^{\min }-e_{2}^{\min }}
$$

It is noted that for the limiting condition, Eq. (27) is identical to Eq. (21).

The derivation above shows that the relationship between maximum and minimum void ratios for a sand-silt mixture is linear. The derived general relationship is shown in Eq. (19) for the coarse-grain dominant region, and shown in Eq. (25) for the fine-grain dominant region. The linear relationship for the coarse-grain dominant region is a function of $e_{1}^{\max }, e_{1}^{\min }, e_{2}^{\max }, e_{2}^{\min }$ and the parameters $a$. The parameter $b$ has no influence on the slope or intercept of this line. On the other hand, the linear relationship for the fine- 
grain dominant region is a function of $e_{1}^{\max }, e_{1}^{\min }, e_{2}^{\max }, e_{2}^{\min }$ and the parameters $b$. The parameter $a$ has no influence on the slope or intercept of this line.

In the following, the derived relationships between maximum and minimum void ratios of a sand-silt mixture are verified with the data of maximum or minimum void ratio versus fines content. Verifications are performed for three cases.

(1) Data are generated by Eqs. 11-14

Assuming a sand-silt mixture has the following properties: The void ratio $e_{1}^{\min }=0.42$ and $e_{1}^{\max }=0.71$ for clean sand, and $e_{2}^{\min }=0.806$ and $e_{2}^{\max }=1.31$ for clean silt. The value of coefficient $a=0.8556$, and coefficient $b=0.8556$. Based on the Eqs. (11-14), the predicted results of maximum and minimum void ratios for various fines contents are computed and plotted in Fig. 8(a). Based on Fig. 8(a), the relationship between $e_{M}^{\max }$ and $e_{M}^{\min }$ for the sand-silt mixture is shown in Fig. 8(b) for the coarse-grain dominant region, and in Fig. 8(c) for the fine-grain dominant region.

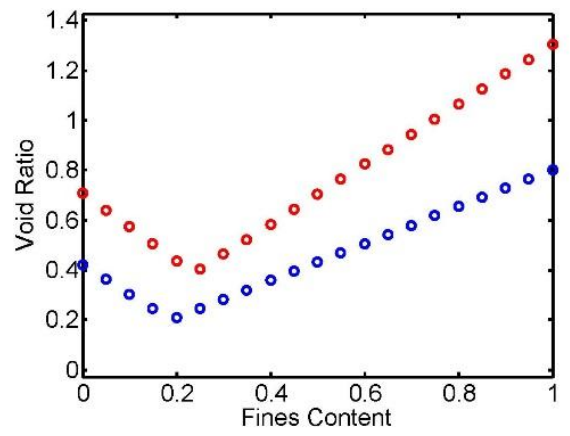

(a)

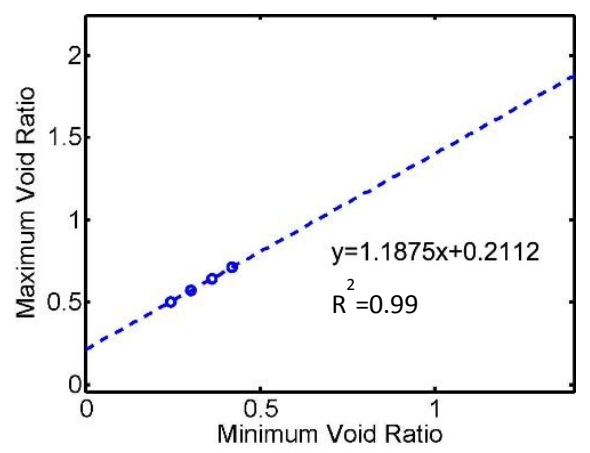

(b)

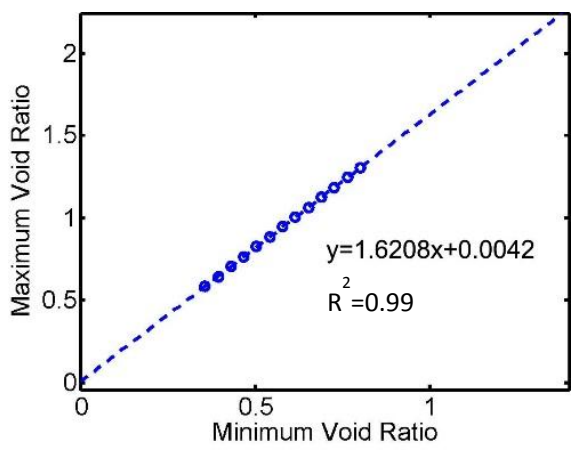

(c)

Fig. 8. (a) Typical results for maximum and minimum void ratios for a binary mixture with various

\section{fines contents. The relationships between $e_{\max }$ and $e_{\min }$ of the mixture for $(\mathrm{b})$ the coarse-grain dominant region, and for (c) the fine-grain dominant region.}

The regressing analysis from Fig. 8(b) shows that the values of $\alpha=1.187$ and $\beta=0.211$, which are exactly equal to the values obtained using Eq. (19). The regressing analysis from Fig. 8(c) shows that the values of $\alpha=1.62$ and $\beta=0.004$ are exactly equal to the values obtained using Eq. (25). Since the data points in Fig. 8(a) is generated from the model, it is not surprising that the relationships plotted from the data points are exactly same as the derived equations. Nevertheless, this comparison has verified the correctness of the derived equations. 
(2) Data are obtained from experimental results (Silica sand-silt mixture 80/100)

In the above example, the data of maximum and minimum void ratio versus fines content are generated from the mathematical model. Here, we use the data from the experimental results on Silica sand-silt

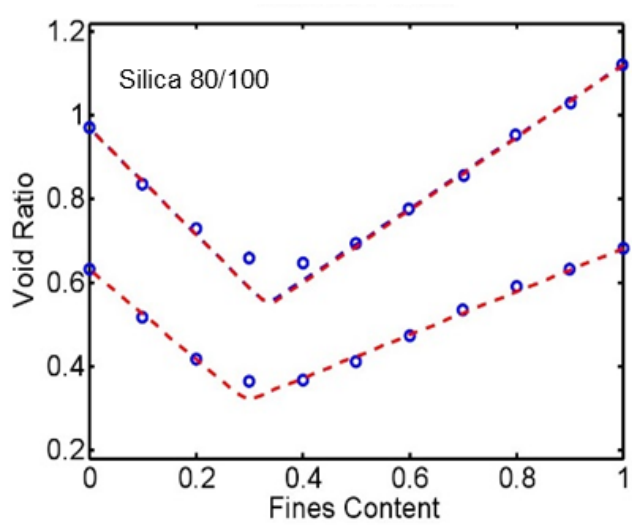

(a)

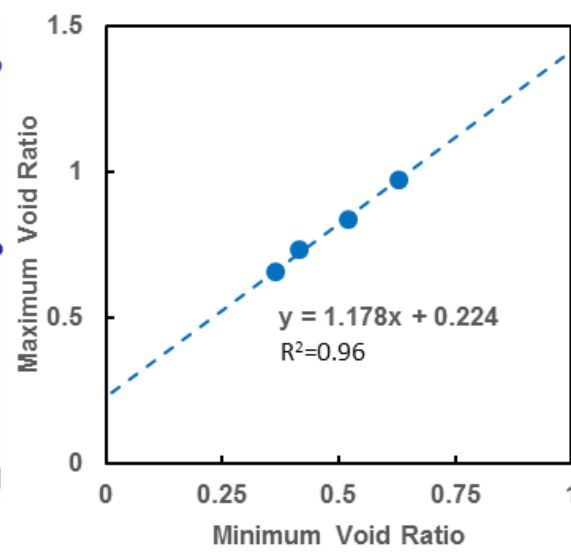

(b)

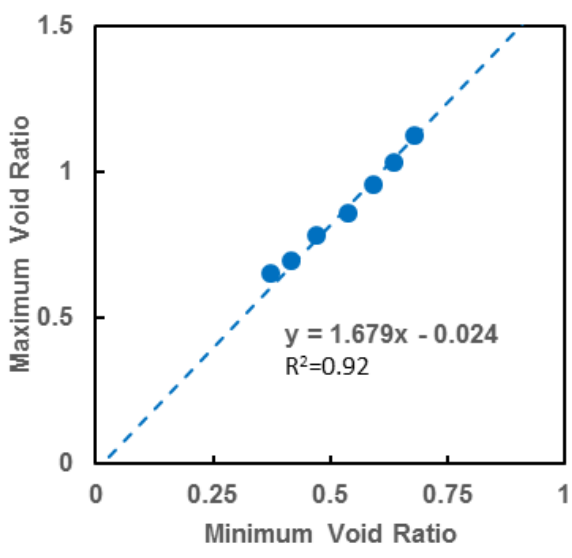

(c)

Fig. 9. (a) Experimental results of maximum and minimum void ratios for various fines contents. The relationships between $e_{\max }$ and $e_{\min }$ of the soil mixture for (b) the coarse-grain dominant region, and for (c) the fine-grain dominant region.

mixture, in which the coarsest grains of $1.08 \mathrm{~mm}$ (between No16-No18 sieves) are mixed with the grains between No.80-No.100 sieves. The measured maximum and minimum void ratios are plotted with hollow circles in Fig. 9(a). The relationship between $e_{M}^{\max }$ and $e_{M}^{\min }$ obtained from the measured data is plotted with solid circles shown in Fig. 9(b) for the coarse-grain dominant region, and in Fig. 9(c) for the fine-grain dominant region.

For this Silica sand-silt mixture, as tabulated in Table 1 , the void ratio $e_{1}^{\min }=0.633, e_{1}^{\max }=0.970$ for clean sand, and $e_{2}^{\min }=0.682, e_{2}^{\max }=1.121$ for clean silt. The values of coefficient $a=0.67$, and coefficient $b=0.74$. The predicted data from the mathematical model are plotted in dash-lines in Fig. 9(a). It is obvious that there are some discrepancies between the measured data points and the model generated dash-lines.

Calculated from Eq. (19), the value of $\alpha=1.178$ and $\beta=0.224$ for coarse-grain dominant region. Calculated from Eq. (25), $\alpha=1.679$ and $\beta=-0.024$ for fine-grain dominant region. The dash-lines in Fig. 9(b) and $9 \mathrm{c}$ are the predicted lines, which fit the experimental data with very good agreement. The coefficient of determination $\mathrm{R}^{2}=0.92-0.96$. Thus, the derived relationships are applicable to the Silica sand-silt mixture.

(3) Data are obtained from 24 types of sand-silt mixtures 

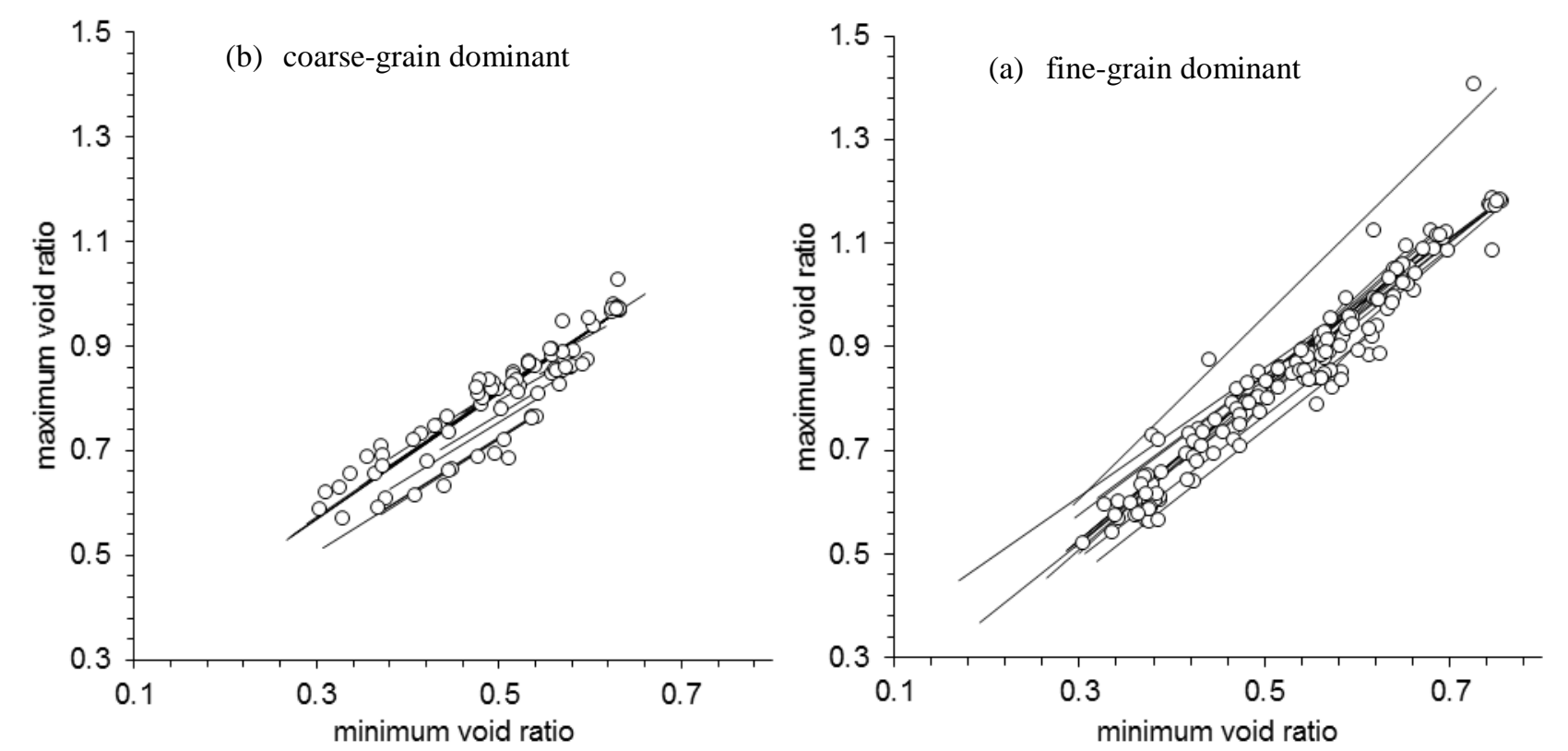

Fig. 10. The measured and predicted relationship between $e_{\max }$ and $e_{\min }$ of 24 soil mixtures listed in Table 1 for the coarse-grain and for the fine-grain dominant regions. 


\section{CONCLUSION}

For a sand-silt mixture, the variation of maximum void ratio with respect to fines content is caused by the same mechanism that influences the variation of minimum void ratio. Using this concept, a mathematical model based on the work by Chang et al. (2015) is developed to be capable of predicting both minimum and maximum void ratios. Using data from 24 types of sand-silt mixtures (about 300 samples with various fines contents), we observed that, for each type of sand-silt mixture, the two material parameters (i.e., the filling coefficient $a$ and the embedment coefficient $b$ ) as determined from the minimum void ratio test results have a strong correlation to that as determined from the maximum void ratio test results. Evaluated from the comparison of predicted and measured void ratios, it is found to be reasonable to hypothesize that the two material parameters, mainly dependent on the geometric characteristics of particles, are same for each type of sand-silt mixture. Thus, the same parameters can be used for predicting both maximum and minimum void ratios of sand-silt mixtures with various fines contents. The model captures well the curve shapes of both maximum void ratio and minimum void ratio versus fines content. The model can also capture the two different values of transitional fines contents for maximum and minimum void ratios.

Based on the mathematical model, linear relationships between maximum void ratio and minimum void ratio have been derived in explicit forms. The linear relationships were found to be different for sand-silt mixtures in the coarse-grain dominant region (i.e. low fines content) and in the fine-grain dominant region (i.e., high fines content). Verifications, using measured results from 24 types of sand-silt mixtures, have demonstrated the applicability of the derived linear relationships.

\section{ACKNOWLEDGEMENT}

This paper was derived from research sponsored by NSF\# CMMI-1537491.

\section{APPENDIX-NOTATION}

The following symbols are used in this paper:

$\alpha=$ the slope of the linear relationship between minimum and maximum void ratios;

$a=$ filling coefficient in the sand-silt mixture;

$a^{\min }, a^{\max }=$ filling coefficient for minimum and maximum void ratio respectively;

$\beta=$ the intercept of the linear relationship between minimum and maximum void ratios;

$b=$ embedment coefficient in the sand-silt mixture;

$b^{\min }, b^{\max }=$ embedment coefficient for minimum and maximum void ratio respectively; 
$e_{1}=$ void ratio of the clean sand;

$e_{2}=$ void ratio of the clean silt;

$e_{M}=$ void ratio of the sand-silt mixture;

$e_{1}^{\text {min }}, e_{1}^{\max }=$ minimum and maximum void ratio of the clean sand;

$e_{2}^{\min }, e_{2}^{\max }=$ minimum and maximum void ratio of the clean silt;

$e_{M}^{\min }, e_{M}^{\max }=$ minimum and maximum void ratio of sand-silt mixture;

$\mathrm{R}^{2}=$ coefficient of determination;

$\Delta V_{v}=$ change of total void volume;

$\Delta V=$ change of total volume of the sand-silt mixture;

$V_{s 1}=$ solid volume of sand;

$V_{s 2}=$ solid volume of silt;

$V_{v}=$ total void volume of the sand-silt mixture;

$V_{v 1}=$ void volume in the packing of clean sand;

$V_{v 2}=$ void volume in the packing of clean silt;

$y_{1}, y_{2}=$ the solid volume fraction for sand and silt respectively;

\section{REFERENCES}

AASHTO T224-86, 1986. Correction for coarse particles in the soil compaction test. AASHTO Designation, 840-845.

A.B., F., G.Papageorigou, 2001. Defining an appropriate steady state line for Merriespruit gold tailings.pdf.

Can. Geotech. J. 706, 695-. doi:10.1139/cgj-38-4-695

Aberg, B., 1992. Void ratio of noncohesive soils and similar materials. J. Geotech. Eng. 118, 1315-1334. doi:10.1061/(ASCE)0733-9410(1992)118:9(1315)

An, X.Z., 2013. Densification of the packing structure under vibrations. Int. J. Miner. Metall. Mater. 20, 499-503. doi:10.1007/s12613-013-0757-9

ASTM D 4253-00, 2002. Standard test method for maximum index density and unit weight of soils using a vibratory table. Annual Book of ASTM Standards. American Society for Testing and Materials, West Conshohocken, PA, pp. 1-14.

ASTM D 4254-00, 2002. Standard test method for minimum index density and unit weight of soils and calculation of relative density. Annual Book of ASTM Standards. American Society for Testing and Materials, West Conshohocken, PA, pp. 1-9 
Bobei, D.C., Lo, S.R., Wanatowski, D., Gnanendran, C.T., Rahman, M.M., 2009. Modified state parameter for characterizing static liquefaction of sand with fines. Can. Geotech. J. 46, 281-295. doi:10.1139/T08122

Cabalar, A.F., Dulundu, K., Tuncay, K., 2013. Strength of various sands in triaxial and cyclic direct shear tests. Eng. Geol. 156, 92-102. doi:10.1016/j.enggeo.2013.01.011

Cabalar, A.F., Mustafa, W.S., 2015. Fall cone tests on clay-sand mixtures. Eng. Geol. 192, 154-165. doi:10.1016/j.enggeo.2015.04.009

Chang, C.S., Wang, J.-Y., Ge, L., 2015. Modeling of minimum void ratio for sand-silt mixtures. Eng. Geol. 196, 293-304. doi:10.1016/j.enggeo.2015.07.015

Cho, A.G., Dodds, J., Santamarina, J.C., 2006. Particle Shape Effects on Packing Density, Stiffness and Strength - Natural and Crushed Sands- Document Summary Number of Words : 4, 266 Number of Tables : 2 Number of Figures : 11. J. Geotech. Geoenvironmental Eng. 132, 591-602. doi:10.1061/(ASCE)1090-0241(2006)132:5(591)

Chu, J., Leong, W.K., 2002. Effect of fines on instability behaviour of loose sand. Géotechnique 52, 751755. doi:10.1680/geot.2002.52.10.751

Cubrinovski, M., Ishihara, K., 2002. Maximum and Minimum Void Ratio Characteristics of Sands. Soils Found. 42, 65-78. doi:10.3208/sandf.42.6_65

De Larrard, F., 1999. Concrete mixture proportioning: a scientific approach. London: Taylor \& Francis, 1999.

Dullien, F.A.L., 1992. Porous media: fluid transport and pore structure, 2nd editio. ed. Academic Press Inc., New York. doi:10.1016/B978-0-12-223651-8.50012-2

Fennis, S.A.A.M., Walraven, J.C., Den Uijl, J.A., 2013. Compaction-interaction packing model: regarding the effect of fillers in concrete mixture design. Mater. Struct. 463-478. doi:10.1617/s11527-012-9910-6

Fourie, A.B., Blight, G.E., Papageorgiou, G., 2001. Static liquefaction as a possible explanation for the Merriespruit tailings dam failure. Can. Geotech. J. 38, 707-719. doi:10.1016/j.soildyn.2005.02.011

Fragaszy, R.J., Sneider, C.A., 1991. Compaction control of granular soils.

Fuggle, A.R., Roozbahani, M.M., Frost, J.D., 2014. Size Effects on the Void Ratio of Loosely Packed Binary Particle Mixtures, in: Geo-Congress 2014 Technical Papers. American Society of Civil Engineers, Reston, VA, pp. 129-138. doi:10.1061/9780784413272.014

Humphres, H.W., 1957. A method for controlling compaction of granular materials.

Japanese Geotechnical Society, 2000. Test method for minimum and maximum densities of sand. Soil Testing Standards, pp. 136-138 (in Japanese).

Kezdi, A., 1979. SOIL PHYSICS. Elsevier, Amsterdam.

Kolbuszewski, J. J., 1948. An experimental study of the maximum and minimum properties of sands. Proceedings, Second International Conference in Soil Mechanics and Foundation Engineering, Rotterdam, Vol. 1, pp 158-165.

Kwan, A.K.H., Fung, W.W.S., 2009. Packing density measurement and modelling of fine aggregate and mortar. Cem. Concr. Compos. 31, 349-357. doi:10.1016/j.cemconcomp.2009.03.006 
Lade, P. V., Liggio, C.D., Yamamuro, J.A., 1998. Effects of Non-Plastic Fines on Minimum and Maximum Void Ratios of Sand. Geotech. Test. J. 21, 336-347. doi:10.1520/GTJ11373J

Larrard, F. de, 1999. Concrete mixture proportioning: A scientifil approach, The effects of brief mindfulness intervention on acute pain experience: An examination of individual difference. E \& FN Spon. doi:10.1017/CBO9781107415324.004

McGeary, 1961. Mechanical Packing of Spherical Particles. J. Am. Ceram. Soc. 44, 513-522. doi:10.1111/j.1151-2916.1961.tb13716.x

Mitchell J. K., 1993. Fundamentals of soil behavior, 2nd edn. Wiley Interscience Publ..

Miurai, K., Maiidali, K., Furukawam, M., Tokiiv, S., 1997. Physical Characteristics of Sands with Different Primary Properties. Soils Found. 37, 53-64.

Monkul, M.M., Ozden, G., 2007. Compressional behavior of clayey sand and transition fines content. Eng. Geol. 89, 195-205. doi:10.1016/j.enggeo.2006.10.001

Mulilis, J.P., Arulanandan, K., Mitchell, J.K., Chan, C.K., Seed, H.B., 1977. Effects of Sample Preparation on Sand Liquefaction. J. Geotech. Eng. Div. 103, 91-108. doi:10.1016/0148-9062(77)90060-2

Peters, J.F., Berney, E.S., 2010. Percolation Threshold of Sand-Clay Binary Mixtures. J. Geotech. Geoenvironmental Eng. 136, 310-318. doi:10.1061/(ASCE)GT.1943-5606.0000211

Polito, C.P., Martin, J.R., 2001. Effects of Nonplastic Fines on the Liquefaction Resistance of Sands 127, 408-415. doi:10.1061/(ASCE)1090-0241(2001)127:5(408)

Powers, T.C., 1968. The properties of fresh concrete. John Wiley \& Sons Inc.

Reed, J.S., 1995. Principles of ceramics processing, 2nd ed. New York: John Wiley \& Sons.

Salgado, R., Bandini, P., Karim, A., 2000. Shear Strength and Stiffness of Silty Sand. J. Geotech. Geoenvironmental Eng. 126, 451-462. doi:10.1061/(ASCE)1090-0241(2000)126:5(451)

Santamarina, J., Cho, G., 2004. Soil behaviour: The role of particle shape. Adv. Geotech. Eng. Proc. Skempt. Conf. 1-14. doi:http://pmrl.ce.gatech.edu/tools/santamarina_cho_2004.pdf

Selig, E., Ladd, R., 1973. Evaluation of Relative Density Measurements and Applications, in: Evaluation of Relative Density and Its Role in Geotechnical Projects Involving Cohesionless Soils. ASTM International, 100 Barr Harbor Drive, PO Box C700, West Conshohocken, PA 19428-2959, pp. 487487-18. doi:10.1520/STP37891S

Smith, L., 2003. Knowledge based system for powder metallurgy. Powder Metall. 46, 9-10. doi:10.1179/003258903765072021

Stovall, T., de Larrard, F., Buil, M., 1986. Linear packing density model of grain mixtures. Powder Technol. 48, 1-12. doi:10.1016/0032-5910(86)80058-4

Tavenas, F., Ladd, R., La Rochelle, P., 1973. Accuracy of Relative Density Measurements: Results of a Comparative Test Program, in: Evaluation of Relative Density and Its Role in Geotechnical Projects Involving Cohesionless Soils. ASTM STP523, pp. 18-60. doi:10.1520/STP37862S

Thevanayagam, S., 1998. Effect of Fines and Confining Stress on Undrained Shear. J. Geotech.

Geoenvironmental Eng. 124, 479-491. doi:10.1061/(ASCE)1090-0241(1998)124:6(479) 
Thevanayagam, S., Shenthan, T., Mohan, S., Liang, J., 2002. Undrained Fragility of Clean Sands, Silty Sands, and Sandy Silts. J. Geotech. Geoenvironmental Eng. 128, 849-859. doi:10.1061/(ASCE)10900241(2002)128:10(849)

Vaid, Y., Negussey, D., 1988. Preparation of Reconstituted Sand Specimens, in: Advanced Triaxial Testing of Soil and Rock. ASTM International, 100 Barr Harbor Drive, PO Box C700, West Conshohocken, PA 19428-2959, pp. 405-405-13. doi:10.1520/STP29090S

Vallejo, L.E., 2001. Interpretation of the limits in shear strength in binary granular mixtures. Can. Geotech. J. 38, 1097-1104. doi:10.1139/t01-029

Westman, A.E.R., Hugill, H.R., 1930. THE PACKING OF PARTICLES1. J. Am. Ceram. Soc. 13, 767-779. doi:10.1111/j.1151-2916.1930.tb16222.x

Yang, S., Lacasse, S., Sandven, R., 2005. Determination of the Transitional Fines Content of Mixtures of Sand and Non-plastic Fines. Geotech. Test. J. 29, 1-6.

Yang, S.L., Sandven, R., Grande, L., 2006. Instability of sand-silt mixtures. Soil Dyn. Earthq. Eng. 26, 183190. doi:10.1016/j.soildyn.2004.11.027

Yilmaz, Y., 2009. A study on the limit void ratio characteristics of medium to fine mixed graded sands. Eng. Geol. 104, 290-294. doi:10.1016/j.enggeo.2008.11.009

Youd, T.L., 1973. Factors Controlling Maximum and Minimum Densities of Sands, in: Evaluation of Relative Density and Its Role in Geotechnical Projects Involving Cohesionless Soils,STP 523. ASTM International, West Conshohocken, PA, pp. 98-112. doi:10.1520/STP37866S

Yu, A.B., Standish, N., 1987. Porosity calculations of multi-component mixtures of spherical particles. Powder Technol. 52, 233-241. doi:10.1016/0032-5910(87)80110-9 
Table 1. List of 33 soil mixtures

\begin{tabular}{|c|c|c|c|c|c|c|c|c|c|c|c|c|c|}
\hline Sand/silt Mixture & $\mathrm{D}_{50}(\mathbf{m m})$ & $\mathrm{d}_{50}(\mathrm{~mm})$ & $\mathbf{d}_{50}: \mathbf{D}_{\mathbf{5 0}}$ & $\mathbf{e}_{\min }(\mathbf{s a n d})$ & $\mathbf{e}_{\min }($ silt $)$ & $\mathbf{e}_{\max }($ sand $)$ & $e_{\max }($ silt $)$ & $\mathbf{a}_{\min }$ & $\mathbf{b}_{\min }$ & $\mathbf{a}_{\max }$ & $\mathbf{b}_{\max }$ & particle shape (coarse) & particle shape (fine) \\
\hline Ottawa F55-crushed silica (R1) & 0.25 & 0.01 & 0.040 & 0.615 & 0.634 & 0.829 & 4.200 & 0.727 & 0.790 & 0.450 & 0.570 & round to subround & angular \\
\hline Ottawa 50/200-Nevada fines (R2) & 0.20 & 0.05 & 0.248 & 0.548 & 0.754 & 0.806 & 1.181 & 0.500 & 0.550 & 0.360 & 0.450 & angular & angular \\
\hline Ottawa F95-Nevada fines (R2) & 0.16 & 0.05 & 0.307 & 0.580 & 0.754 & 0.868 & 1.179 & 0.180 & 0.300 & 0.155 & 0.222 & subround & angular \\
\hline Ottawa C109-Silica fins (R3) & 0.39 & 0.01 & 0.031 & 0.500 & 1.800 & & & 0.840 & 0.890 & & & subround & \\
\hline Ottawa C109-Kaolinite (R3) & 0.39 & 0.00 & 0.003 & 0.500 & 0.600 & 0.825 & 1.300 & 0.990 & 0.890 & 0.650 & 0.400 & subround & \\
\hline Foundry (R4) & 0.25 & 0.01 & 0.040 & 0.608 & 0.627 & 0.800 & 2.100 & 0.725 & 0.796 & 0.520 & 0.530 & round to subround & angular \\
\hline Nevada sand-ATC silt (R5) & 0.14 & 0.04 & 0.257 & 0.642 & 0.877 & & & 0.382 & 0.467 & & & subangular & angular \\
\hline Nevada 50/200-Nevada fines (R2) & 0.14 & 0.04 & 0.314 & 0.570 & 0.754 & 0.878 & 1.181 & 0.240 & 0.320 & 0.190 & 0.250 & subangular & angular \\
\hline Nevada 50/80-Nevada fines (R6) & 0.21 & 0.05 & 0.237 & 0.581 & 0.754 & 0.855 & 1.183 & 0.430 & 0.640 & 0.290 & 0.540 & \multirow{3}{*}{\multicolumn{2}{|c|}{ subangular to angular }} \\
\hline Nevada 80/200-Nevada fines (R6) & 0.12 & 0.05 & 0.417 & 0.617 & 0.754 & 0.938 & 1.169 & 0.150 & 0.200 & 0.102 & 0.130 & & \\
\hline Nevada 50/80 - Nevada80/200+fines (R6) & 0.17 & 0.05 & 0.302 & 0.581 & 0.754 & 0.876 & 1.180 & 0.290 & 0.320 & 0.185 & 0.260 & & \\
\hline Toyoura (R7) & 0.17 & 0.01 & 0.059 & 0.591 & 0.609 & & & 0.443 & 0.229 & & & elongated sub-angular & angular \\
\hline Hokksund (R8) & 0.45 & 0.04 & 0.078 & 0.570 & 0.760 & 0.949 & 1.413 & 0.534 & 0.714 & 0.880 & 0.620 & sharp edges, cubical & angular, subangular \\
\hline MGM (R9) & 0.12 & 0.01 & 0.078 & 0.755 & 1.000 & 1.247 & 2.740 & 0.380 & 0.724 & 0.335 & 0.680 & highly angular to subround & thin and plate-like \\
\hline Vietnam (R10) & 0.16 & 0.02 & 0.144 & 0.607 & 0.596 & 0.808 & 1.849 & 0.544 & 0.678 & 0.560 & 0.600 & subangular & subangular \\
\hline Cambria-Nevada fines (R6) & 1.50 & 0.05 & 0.033 & 0.538 & 0.754 & 0.765 & 1.176 & 0.650 & 0.820 & 0.685 & 0.760 & round & angular \\
\hline Ottawa C109-Silica sand (R3) & 0.39 & 0.15 & 0.385 & 0.500 & 0.425 & 0.826 & 0.800 & 0.420 & 0.200 & 0.460 & 0.270 & subround & subround \\
\hline Vietnam (R10) & 0.37 & 0.16 & 0.432 & 0.552 & 0.583 & 0.703 & 0.755 & 0.096 & 0.243 & 0.100 & 0.220 & subangular & subangular \\
\hline Cambria-Nevada 50/80 (R6) & 1.50 & 0.21 & 0.141 & 0.538 & 0.581 & 0.765 & 0.854 & 0.450 & 0.570 & 0.500 & 0.470 & round & subangular \\
\hline Cambria-Nevada 80/200 (R6) & 1.50 & 0.12 & 0.080 & 0.538 & 0.624 & 0.768 & 0.937 & 0.480 & 0.590 & 0.550 & 0.610 & round & angular \\
\hline Nevada 50/80- Nevada 80/200 (R6) & 0.21 & 0.12 & 0.569 & 0.581 & 0.617 & 0.854 & 0.938 & 0.080 & 0.060 & 0.070 & 0.140 & \multirow{13}{*}{\multicolumn{2}{|c|}{ subangular to angular }} \\
\hline Silica\#16-\#18 (R11) & 1.08 & 1.08 & 1.000 & 0.633 & 0.633 & 0.970 & 0.970 & 0.000 & 0.000 & 0.000 & 0.000 & & \\
\hline Silica\#16-\#18 \#18-\#30 (R11) & 1.08 & 0.78 & 0.722 & 0.633 & 0.615 & 0.970 & 0.984 & 0.030 & 0.035 & 0.062 & 0.052 & & \\
\hline Silica\#16-\#18 \#30-\#50 (R11) & 1.08 & 0.40 & 0.370 & 0.633 & 0.644 & 0.970 & 1.048 & 0.420 & 0.350 & 0.353 & 0.360 & & \\
\hline Silica\#16-\#18 \#30-\#80 (R11) & 1.08 & 0.42 & 0.389 & 0.633 & 0.590 & 0.970 & 0.996 & 0.410 & 0.360 & 0.350 & 0.345 & & \\
\hline Silica\#16-\#18 \#50-\#80 (R11) & 1.08 & 0.26 & 0.244 & 0.633 & 0.696 & 0.970 & 1.114 & 0.530 & 0.500 & 0.525 & 0.530 & & \\
\hline Silica\#16-\#18 \#80-\#100 (R11) & 1.08 & 0.17 & 0.155 & 0.633 & 0.682 & 0.970 & 1.121 & 0.670 & 0.740 & 0.670 & 0.730 & & \\
\hline Silica\#16-\#18 \#80-\#120 (R11) & 1.08 & 0.14 & 0.127 & 0.633 & 0.697 & 0.970 & 1.124 & 0.690 & 0.750 & 0.685 & 0.770 & & \\
\hline Silica\#16-\#18 \#80-\#200 (R11) & 1.08 & 0.10 & 0.095 & 0.633 & 0.651 & 0.970 & 1.084 & 0.840 & 0.740 & 0.725 & 0.816 & & \\
\hline Silica\#16-\#18 \#100-\#120 (R11) & 1.08 & 0.14 & 0.127 & 0.633 & 0.697 & 0.970 & 1.125 & 0.880 & 0.738 & 0.714 & 0.814 & & \\
\hline Silica\#16-\#18 \#100-\#200 (R11) & 1.08 & 0.10 & 0.095 & 0.633 & 0.668 & 0.970 & 1.084 & 0.890 & 0.810 & 0.770 & 0.880 & & \\
\hline Silica\#16-\#18 \#120-\#200 (R11) & 1.08 & 0.10 & 0.090 & 0.633 & 0.682 & 0.970 & 1.115 & 0.710 & 0.720 & 0.800 & 0.980 & & \\
\hline Silica\#16-\#18 \#200-\#400 (R11) & 1.08 & 0.06 & 0.053 & 0.633 & 0.700 & 0.970 & 1.091 & 0.900 & 0.940 & 0.770 & 0.895 & & \\
\hline
\end{tabular}

R1: Thevanayagam 2007; R2: Lade \& Yamamuro 1997; R3: Pitman et al. 1994; R4: Thevanayagam et al. 2002; R5: Yamamuro \& Covert 2001; R6: Lade et al. 1998; R7: Zlatovic \& Ishihara 1997

R8: Yang 2004; R9: Fourie \& Papageorgiou 2001; R10: Cho 2014; R11: Yilmaz 2009 